1 The UK Health Alliance on Climate Change

Cite this as: $B M J 2021 ; 375: n 3000$ http://dx.doi.org/10.1136/bmj.n3000 Published: 03 December 2021

\title{
Australia, a laggard in responding to climate change, produces an impressive report on climate change and health
}

\section{Richard Smith chair}

Australia is one of the countries most at risk from climate change, but is a laggard in responding, says an impressive report, Climate Change and Australia's Healthcare Systems, from the Royal Australasian College of Physicians (RACP) with endorsement from 10 colleges.

"We are," says the report," especially vulnerable to economic shocks and "catastrophic" weather events in a world that is both warming and decarbonising. Australia faces an increase in temperature over preindustrial levels of $6 \mathrm{C}$ by 2100 , but a rise of $3 \mathrm{C}$ "would render Australia's ecological systems unrecognisable due to alterations in the distribution or loss of thousands of species."

"Our leaders do need to make a decision about how they're going to manage climate change and its effects on the healthcare sector," says RACP president John Wilson. "Now, if you wish to sit on the railway line and wait until it happens, then there is an enormous price to pay."

The whole world watched the Australian bushfires of 2019-20, and the smoke alone was responsible for more than 400 excess deaths and over 3000 hospitalisations for cardiovascular and respiratory problems. The smoke reached as far as South America, and the total health costs are estimated to be AUD \$1.95 billion, with longer term health impacts still unknown. The fires followed on from two years of intense drought.

An economic evaluation included in the report, based on conservative assumptions, found that bushfires will over the next 10 years kill more than a thousand people, cost the broader Australian economy $\$ 10$ billion (discounted), and the health system $\$ 69$ million.

Australian Aboriginal people arrived on the continent some 50 ooo years ago and lived in harmony with what are often harsh climate conditions. Europeans arrived a little over 200 years ago, and now "without action to stop climate change, [Aboriginal] people will be forced to leave their country and leave behind much of what makes them Aboriginal." At the same time Torres Strait Islanders are suffering extreme distress because their islands are already regularly affected by coastal erosion and saltwater inundation.

Geography and weather patterns intensify the Urban Heat Island effect and bring extreme heat to Western Sydney. In January 2020, Penrith was the hottest place on Earth at $48.9^{\circ} \mathrm{C}$, and in 2019 Parramatta sweltered through 47 days with temperatures over $35^{\circ} \mathrm{C}$.

Australians have one of the world's highest per capita emissions of greenhouse gases at 16.9 tons of carbon dioxide equivalent per year compared with 5.6 tons for the UK and 2 tons for India. In the 2021 Sustainable Development Report, Australia ranked last for carbon and energy policy. Yet, with its abundant renewable resources (not least sunlight) Australia is, reported the OECD, "uniquely placed to benefit economically from global decarbonisation.”

The health system in Australia accounts for about $7 \%$ of the nation's emissions compared with a global average of $4.4 \%, 6 \%$ for the UK and $10 \%$ for the USA. An analysis of 101 countries published in the 2019 Lancet Countdown found that most had a national climate and health strategy, but Australia did not, although there are many responses within different parts of the health system. A 2021 analysis by the Global Climate and Health Alliance of how nations are including health in their commitments under the Paris Agreement gave Australia a score 0/15.

At COP26 in Glasgow some 50 countries committed to building climate resilient and low carbon health systems, but Australia was not one of them. ${ }^{2}$

This poor performance is despite widespread calls from health experts and health stakeholders since 2010 for a coordinated national response to the health impacts of climate change, calls that have intensified in recent years. Australia was the first country in the world to have a professor of planetary health.

Part of the report from the Royal Australian College of Physicians is a systematic review of health system responses to climate change. The review found 34 responses, and evidence from higher quality reviews reports a broad range of beneficial interventions including:

- Training of healthcare workers to improve environmental performance of hospitals reduces chemical use, waste disposal and surgical costs.

- Energy efficiency measures which lead to water and energy savings can save millions of dollars for hospitals.

- Recycling in operating rooms, dialysis centres, and across hospitals can generate financial savings.

- Telemedicine reduces carbon footprint, hospital referrals, and more costly face-to-face consultations.

- Substituting desflurane in anaesthesia for lower polluting agents reduces the greenhouse gas contribution of anaesthetic gases in operating theatres from 51 to $63 \%$ to $4 \%$.

- Compared with clothing that is reused, disposable clothing has a $200-300 \%$ higher carbon footprint, 
$250-300 \%$ greater water need, and $750 \%$ greater impact on solid waste production.

- Reprocessing single-use devices in the USA saves \$471 million each year and 7000 tons of medical waste

- System level responses have the most potential for impact, but very few published examples exist.

The report identifies that research on climate change and health is limited and recommends that there be much more.

An analysis of what is needed for an effective health system response to climate change is included in the report. Leadership and prevention are key. Collaboration and systems-based approaches are needed, and actions must be based on evidence. Clear accountability frameworks facilitate a rapid learning healthcare system, but there must be development in capacity and a recognition that diverse knowledge, some of it unfamiliar to health professionals is needed.

The colleges' report recommends that Australia implement and fund a coordinated national strategy on climate change and health and commit to achieving a net-zero health system by 2040. Research is needed and capacity must be built. The knowledge and leadership of Aboriginals and Torres Strait Islanders should be embedded in climate health policy and action, and investing in prevention and early intervention must be a key element of climate health action.

The federal government has committed to reaching net zero emissions by 2050. The Australian prime minister Scott Morrison has said the government's net zero plan is "responsible" and "practical," although he has also said that the coal industry will be "around for decades to come."3

Karen Price, the president of the Royal Australian College of General Practitioners, said there was a clear need for the Australian government to commit to stronger 2030 emissions targets. "Climate change is a health emergency."

The full report is available at https://www.racp.edu.au/docs/defaultsource/advocacy-library/climate-change-and-australias-healthcaresystems-a-review-of-literature-policy-and-prac-

tice.pdf?sfvrsn=efe8c61a_4 and a recording of the webinar to launch the report will soon be available at https://www.racp.edu.au/advocacy/policy-and-advocacy-priorities/climate-change-and-health

Competing interest: RS is chair of the UK Health Alliance on Climate Change and spoke at the launch of the report. He was not paid and spoke by Zoom from London, so making only a tiny emission of greenhouse gases.

Provenance and peer review: not commissioned, not peer reviewed

1 Climate Change and Australia's Healthcare Systems https://www.racp.edu.au/docs/defaultsource/advocacy-library/climate-change-and-australias-healthcare-systems-a-review-of-literaturepolicy-and-practice.pdf?sfvrsn=efe8c61a_4

2 Countries commit to develop climate-smart health care at COP26 UN climate conference https://www.who.int/news/item/09-11-2021-countries-commit-to-develop-climate-smart-healthcare-at-cop26-un-climate-conference

3 Scott Morrison says coal industry will be around for 'decades to come' https://www.sbs.com.au/news/scott-morrison-says-coal-industry-will-be-around-for-decadesto-come/4adf402c-bf32-497f-8a53-459a14640ed1 